\title{
Regulação das responsabilidades parentais: Discursos dos magistrados sobre a prática pericial
}

\author{
Andreia Machado ${ }^{1}$, Marlene Matos ${ }^{1}$, \\ ${ }^{1}$ Escola de Psicologia, Universidade do Minho
}

\begin{abstract}
Resumo: A avaliação psicológica no âmbito da regulação das responsabilidades parentais é uma das áreas mais exigentes da prática forense, devido ao conflito e à carga emocional que lhe estão subjacentes. A lei concede aos magistrados a opção de recorrer à perícia psicológica como auxiliar da sua tomada de decisão. Com o intuito de conhecer a valoração e o impacto que as perícias psicológicas têm na decisão judicial, analisaram-se os discursos de dez magistrados, com recurso ao programa Nvivo. Os resultados permitiram concluir que a perícia psicológica se assume como um importante instrumento auxiliar da decisão judicial. No cômputo geral, os participantes manifestaram-se satisfeitos com a prática pericial, nomeadamente com a sua objetividade, exaustividade e fundamentação, sublinhando, no entanto, a necessidade de uma maior celeridade na sua emissão e de um maior cuidado ao nível da linguagem utilizada. Os laços entre a Psicologia e o Direito estão atualmente mais estreitos.
\end{abstract}

Palavras-chave: Regulação das responsabilidades parentais; Magistrados; Prática pericial; Impacto.

Child custody evaluation: perceptions of judges about the psychological forensic assessment: Psychological assessment in child custody evaluation is one of the most demanding areas of forensic practice due to the conflict and emotional distress it carries. Law allows the use of psychological reports as an auxiliary mean in the decision act. In order to know the impact of the psychological report in their practice, we requested the collaboration of ten magistrates and analyze their perceptions and discourses about psychological forensic practice. The data collected were analyzed with the support of the program Nvivo. The results revealed that psychological reports are an important working toll for decision-making process among participants. It's also important to notice that, in general, judges are very pleased with forensic practice, despite their appeal for more celerity in their execution and more precision in terms of language. The relationships between Psychology and Law are currently narrower.

Keywords: Child custody evaluation; Magistrates; Psychological forensic assessment, Impact.

É possível encontrar na literatura diversas definições de regulação das responsabilidades parentais (RPP), não existindo uma definição clara e inequívoca (Pereira \& Matos, 2011). A lei, apesar de não elencar criteriosamente os poderes-deveres dos progenitores para prover o superior interesse da criança, através do art. 1878. ㅇ do C.P.C. enumera alguns pilares em que estes têm de assentar, nomeadamente o cuidado com a segurança, a saúde, o sustento, a educação, a representação e a administração dos bens do(s) menor(es). Além disso, os artigos 69.. , n. 1 e 36. , n.o 5 da Constituição da República Portuguesa plasmam, quer o direito da criança ao seu desenvolvimento integral, quer ao dever de educação dos filhos que se impõe aos pais.

De acordo com a lei comummente apelidada de "lei do divórcio" (lei n.o 61/2008), estas responsabilidades parentais são partilhadas e o seu exercício é comum. No entanto, quando algum dos papéis anteriormente referidos é quebrado, a lei concede ao outro progenitor o direito de recorrer ao art. 181. ${ }^{\circ}$, n. -1 da O.T.M., tendo lugar um processo de incumprimento das responsabilidades parentais. 0 sistema judicial prevê, também, a ocorrência de um pedido de alteração da RRP, através do art. 182.ํㅡ, n.․․ 1 da O.T.M. (Ramião, 2005).

No caso de não existir consenso entre os pais sobre o destino e guarda dos menores, fica a cargo do tribunal determinar a modalidade de guarda a exercer (Ackerman, 1999; Antunes, Caridade, \& Pereira 2005; Ribeiro, 2007; Sottomayor, 2004). As três modalidades de guarda em vigor são: única, alternada ou conjunta. Embora em teoria a guarda conjunta se afigure como ideal para a criança, assiste-se ainda a uma predileção pela guarda única (Bricklin, 1995; Sottomayor, 2004).

A jurisprudência indica aos Tribunais que o critério a seguir para a tomada de decisão é o superior

${ }^{1}$ Dados de contacto para correspondência: Andreia Machado, Escola de Psicologia, Universidade do Minho, 4710-057 Braga. E-mail: andreiamachado@psi.uminho.pt. 
interesse da criança. Este é um conceito jurídico indeterminado, "a preencher através de juízos de valor e de experiência que, em face do caso concreto, determinam a escolha de uma solução e não de outra" (Sottomayor, 2003, p. 74, como citado em Simões, Martins, \& Formosinho, 2006), devendo, pois, ser aplicado a um nível singular e não geral. Contudo, há certos princípios que regem a aplicação deste conceito. É de notar que o processo de decisão tendo por base o superior interesse da criança tem início pela eliminação e não pela seleção, ou seja, o progenitor que tenha a seu desfavor alguns aspetos, como a título de exemplo, pôr em risco a vida do menor, maus-tratos, negligência, entre outros, é excluído (Ackerman, 1999; Ribeiro, 2007; Simões et al., 2006; Sottomayor, 2004). Em seguida, elencam-se os aspetos relativos à criança (e.g., a satisfação das suas necessidades físicas, religiosas, intelectuais e materiais, a sua idade, sexo e grau de desenvolvimento físico e psíquico, etc.), aos progenitores (e.g., a capacidade dos pais para satisfazer as necessidades dos filhos, o tempo disponível para cuidar destes, a saúde física e mental dos pais, a continuação da relação de cada um dos pais com a criança, o afecto que cada um dos pais sente pela criança, o seu estilo de vida, etc.), tendo-se ainda em conta as condições geográficas, habitacionais, entre outras (Ackerman, 1999; Simões et al., 2006; Sottomayor, 2004).

Sendo na verdade estes factores tantos e tão variados como os casos que surgem perante o Tribunal, sugere-se que a jurisprudência demande o levantamento e a apreciação de dados ou informações por profissionais especializados, quer sejam da área do serviço social, da psicologia e/ou da psiquiatria, para a tomada de decisão acerca do tipo de guarda a atribuir (e.g., Kurk, 2011; Simões et al., 2006). Assim, o magistrado não sendo especialista nas questões supramencionadas e suscetíveis de avaliação por estes profissionais, pode solicitar o seu auxílio, o que aumenta a validade da sua decisão (Ackerman, 1996; Akre, 1992; Clark, 1995; Gindo, 1995; Manita \& Machado, 2010; Roseby, 1995, como citado em Krauss \& Sales, 2000). Note-se, porém, que as perícias requeridas em processos de RRP não são vinculativas.

Nesse sentido, o momento da decisão é um privilégio-ónus incontestavelmente do juiz (Ribeiro, Sampaio, \& Amaral, 1992) e, enquanto decisor último, é o responsável por tomar uma decisão conjugando a lei e a apreciação da prova (Ribeiro et al.,1992). A tomada de decisão judicial, não é no entanto, um processo puramente racional que ocorre no "vazio", sendo o resultado da conjugação de diversos fatores, subjetivos, pessoais, sociais, culturais e contextuais (Manita \& Machado, 2010). Como defende Braman (2010, como citado em Manita \& Machado, 2012), o juiz tem a responsabilidade de tentar diminuir o erro na tomada de decisão, já as ciências sociais, em particular a Psicologia, têm o papel de estudar as caraterísticas, dinâmicas e limitações da tomada de decisão judicial, de forma a coadjuvar os magistrados a tomar decisões de forma mais sustentada.

Assim, aos psicólogos forenses cabe o papel de "conhecer, compreender e atribuir significado às informações que obtêm junto dos pais, da criança ou de outras fontes conhecedoras da situação como, por exemplo, professores, vizinhos, colegas e familiares das partes envolvidas no processo" (APA, 2004; Clark, 1995, como citado em Simões et al., 2006, p. 507). Esta informação far-se-á chegar ao Tribunal por intermédio de relatórios, pareceres ou perícias, constituindo-se dessa forma elementos oportunos para auxiliar a decisão judicial de acordo com o superior interesse do menor (Kirkland \& Kirkland, 2001; Ramião, 2005; Simões et al., 2006).

É, deste modo, que a Psicologia Forense pode colaborar com o sistema judicial. No caso dos processos de RRP, as avaliações forenses visam aquilatar o superior interesse da criança, através de uma avaliação completa, imparcial e neutra, da dinâmica das relações familiares, considerando a personalidade e o carácter dos intervenientes (Ramião, 2005). Vários são os autores (e.g., Antunes et al., 2005; Pereira \& Matos, 2011) que entendem que nestes processos se devem avaliar vários parâmetros: a capacidade parental dos progenitores; os conhecimentos, competências e atributos de cada um necessários para o exercício das responsabilidades parentais, bem como para o seu ajustamento psicológico e a sua capacidade para supressão das necessidades do(s) menor(es); a interação do(s) menor(es) com os progenitores; a capacidade de antecipação por parte dos progenitores em relação às necessidades futuras do(s) filho(s); as condições que possui cada progenitor para conceder um ambiente familiar estável e caloroso ao(s) menor(es); a possibilidade de existência de condutas inapropriadas que possam influenciar o bom desenvolvimento do(s) menor(es); e a presença ou não de psicopatologia em ambos os pais.

Este tipo de avaliação que, por norma, se executa através de um protocolo extenso e complexo, tem início quando o psicólogo é convocado pelo Tribunal para a realização dessa avaliação (e.g., avaliação das capacidades parentais, avaliação do desenvolvimento do menor). Seguidamente é traçado um plano de trabalho (i.e., fontes a entrevistar, fontes colaterais, instrumentos a administrar), o qual, depois de executado, resulta num relatório pericial ou perícia (i.e., num conjunto de procedimentos interpretativos) em que é explicitada a metodologia e fontes utilizadas, a informação recolhida, uma conclusão face aos quesitos enunciados e algumas recomendações finais (Antunes et al., 2005; Simões et al., 2006). 
É de salientar, contudo, que a prática psicológica forense, no plano nacional, e mais concretamente na área da RRP nem sempre foi tão estruturada e sistematizada como acontece atualmente. 0 principal ponto de viragem a este nível deve-se ao aparecimento, no decorrer dos últimos 20 anos, de múltiplos modelos de avaliação que nomeiam áreas preferenciais de avaliação (e.g., Antunes et al., 2005; Fariña, Arce, Seijo, \& Novo, 2002; Marin, Esparcia, \& Bartumeus, 2008; O'Connor, Marvin, \& Whelan, 2005). São de salientar as propostas apresentadas a este respeito pela American Psychological Association (1994), pela Association of Family and Conciliation Courts (Sthal, 1994) e ainda pela American Academy of Child and Adolescent Psychiatry (1997; Ackerman, 1995; 1999; Connell, 2006).

A condução de uma avaliação psicológica em casos de RRP é um processo dispendioso em termos de tempo, tanto para os peritos como para os avaliados. Aliás, de acordo com a literatura, frequentemente envolve uma média de 19 a 21 horas de avaliação (desde a realização da primeira entrevista até à conclusão do relatório pericial) até que o processo seja finalizado (Emery, Otto, \& O’Donohue, 2005, como citado em Correia, 2008). De acordo com Bow e Quinnell (2002) há um conjunto de diretrizes que norteiam uma boa prática pericial a este nível: o relatório pericial deve ser conciso, de fácil leitura e englobar as seguintes áreas: a) a lista de todas as entrevistas e observações efetuadas, incluindo as datas de realização, o nome dos sujeitos envolvidos e o local onde ocorreram; b) a lista das fontes contactadas; c) o desenvolvimento do relatório, que deve abranger o nome, idade, habitação atual, família de origem, nível de instrução, profissão, saúde física e mental, rede social, presença de abuso de substâncias e história criminal dos avaliados, assim como deve conter informação sobre as variáveis pais-criança: interações, competências parentais, preferência infantil, etc.; d) descrição da interação e observações efetuadas entre os progenitores e o(s) menor(es); e) descrição da informação obtida através de cada uma das fontes colaterais consultadas; f) descrição dos instrumentos utilizados e justificação para a seleção dos mesmos; g) recomendações sobre a guarda e regime de visitas, podendo ainda sugerir recomendações complementares (e.g., acompanhamento psicológico para alguma das partes).

De notar que, internacionalmente, os psicólogos são os profissionais a quem os magistrados mais recorrem nos casos de RRP (e.g., Bow \& Quinnell, 2001). Também em Portugal se assiste a esta procura crescente (e.g., Manita \& Machado, 2012). No nosso país, não obstante a existência de gabinetes privados criados para esse efeito, as perícias psicológicas são maioritariamente levadas a cabo por instituições públicas, que envolvem as unidades especializadas da Segurança Social - Equipa Multidisciplinar de Assessoria aos Tribunais (E.M.A.T.) e os serviços de psicologia de algumas universidades. A título ilustrativo, a Universidade do Minho, contexto onde se insere a Unidade de Psicologia da Justiça da Universidade do Minho, tem registado um aumento de pedidos para a realização de perícias psicológicas, designadamente neste âmbito (Gonçalves, 2010), tendo o número de pedidos judiciais de RRP crescido 57,1\%, de 1998 para 2007 (Caridade, Machado \& Gonçalves, 2008).

Provavelmente, estes números estão relacionados com o aumento do número de divórcios, uma vez que segundo os dados oficiais mais recentes o número de divórcios decretados aumentou e o número de casamentos realizados diminuiu. Em concreto, o número de casamentos tem vindo a diminuir, com especial incidência a partir de 2000 (INE, 2009). Segundo os dados mais recentes do Instituto Nacional de Estatística, foram celebrados 31998 casamentos em 2013. Divórcios foram 22 525, o que corresponde a uma percentagem de 70,4 por cento. Nos últimos três anos, a percentagem de divórcios em relação aos casamentos celebrados tem-se mantido nos 70 por cento.

Assiste-se, portanto, a uma nova realidade social em todas as sociedades europeias que modificou a forma de vivenciar a família e a conjugalidade (Ackerman, 1995; Catalán et al., 2008; Pinto \& Pereira, 2005; Torres, 1996) ocorrendo uma transição do modelo de família tradicional para o de família moderna (Santos, 2003). Nos últimos anos, surgiram vários modos de conceptualizar a família e/ou de a organizar e estruturar (Relvas \& Alarcão, 2002). São, aliás, estas novas formas de família, demarcadas por divórcios e posteriores reorganizações familiares, que dão origem a novos modos de exercer a parentalidade (coparentalidade, monoparentalidade; Kreeger, 2003; Relvas \& Alarcão, 2002). De qualquer modo, "em termos sociais, o divórcio é um dos fenómenos que mais contribui para a monoparentalidade e para a ausência de contactos dos filhos com um dos progenitores" (Pinto \& Pereira, 2005, p. 17). Além disso, o divórcio está associado demasiadas vezes a um elevado grau de conflito entre os progenitores, o qual se reflecte na hora de decidir o futuro dos seus filhos (Charlish, 1997; Pinto \& Pereira, 2005). A este respeito, é importante referir, que em 2013, foram 16510 os processos de regulação do exercício das responsabilidades parentais e 21765 os pedidos de alteração e de incumprimento da RRP. Por cada regulação existe 1,3 processos de incumprimento (Direção Geral da Política da Justiça, 2014).

Apesar do evidente aumento de pedidos de avaliações psicológicas forense nos casos de RRP, a verdade é que se desconhece a valoração e o impacto que estas têm na decisão final dos magistrados. Trata-se, pois, de uma área pouco explorada na literatura, reflexo provavelmente da reduzida investigação empírica nesse domínio. 
No nosso país, a literatura tem-se focado sobretudo nas questões sociológicas (e.g., Delgado, 1996; Torres, 1996) e jurídicas (Santos, 2003; Simões et al., 2006; Sottomayor, 2004). Existem ainda alguns trabalhos sobre a avaliação psicológica na RRP (Antunes et al., 2005; Pereira \& Matos, 2011; Simões et al., 2006) e o impacto do divórcio para os envolvidos (Pinto, 2002; Pinto \& Pereira, 2005; Ribeiro, 2007). Constata-se, assim, uma escassez de trabalhos empíricos realizados acerca da prática pericial e do seu impacto na decisão judicial. A nível internacional, os parcos estudos, apesar de muito datados (e.g., Lowery, 1981; Reidy et al., 1985; Ash \& Guyer, 1986) indicam uma evolução no sentido de a perícia constituir um instrumento de auxílio muito importante para os magistrados.

Face a este estado da arte, desde 2007, a Escola de Psicologia da Universidade do Minho tem produzido estudos sobre a prática pericial e o impacto nas decisões judiciais (e.g., Correia, 2008; Pereira \& Matos, 2010). Este trabalho é um exemplo disso.

Este estudo, de caráter exploratório, enquadra-se numa investigação mais ampla em curso na Escola de Psicologia da Universidade do Minho sobre a Regulação das Responsabilidades Parentais. Sendo esta uma investigação de cariz qualitativo, foram elaborados objetivos operacionais que orientaram a mesma. Com o intuito de compreender o papel das perícias psicológicas no processo de tomada de decisão judicial, as questões de partida que presidiram ao estudo empírico foram: quais são as perceções dos magistrados acerca da prática psicológica pericial? Que tipo de valoração fazem dessa prática? Qual é o reflexo da perícia psicológica na sentença? Qual é o seu impacto na decisão judicial?

\section{MÉTODO}

\section{Participantes}

Dez magistrados da região Norte do país, de diferentes juízos de competência (e.g., judiciais e de família e menores) participaram neste estudo. Os participantes tinham em média 31 anos, quatro participantes eram do sexo feminino e seis eram do sexo masculino. A maioria era casado/a $(\mathrm{N}=6)$, seguido do grupo de magistrados solteiros $(\mathrm{N}=3)$, sendo que apenas um era divorciado. Em termos de experiência enquanto magistrados, tinham em média 13 anos de exercício de magistratura.

Não estabelecemos à priori um número de participantes. A recolha e o tratamento de dados (i.e., as entrevistas, a sua codificação e respetiva análise) decorreram simultaneamente até ao momento em que não surgiram novas categorias de significado na análise das entrevistas.

\section{Procedimentos e instrumento}

Para a seleção dos participantes, o critério adotado foi a anterior solicitação, no âmbito de processos de RRP, de avaliações psicológicas forenses à Unidade de Psicologia da Justiça da Universidade do Minho. Assim, através de ofício dirigido aos tribunais, solicitámos para este estudo a participação de magistrados com quem já tínhamos colaborado no âmbito de perícias psicológicas executadas.

Uma vez anuído o pedido, era apresentado ao participante um formulário de consentimento informado onde constava informação sobre os objetivos da investigação, a confidencialidade dos dados e implicações da participação no estudo.

Com o intuito de aceder ao discurso dos magistrados elaborámos um guião de entrevista semiestruturado. 0 guião era composto por dezoito questões organizadas em três etapas distintas. A entrevista tinha início com questões introdutórias sobre a RRP (e.g., posição face ao conceito "superior interesse da criança"). Posto isto, as primeiras questões visavam uma caraterização das perícias psicológicas em geral. Num segundo momento, o objetivo era perceber qual o valor e o impacto da perícia na decisão judicial. Por fim, abordava-se a relação entre a Psicologia e o Direito, abrindo lugar para sugestões e críticas que permitissem melhorar o desempenho dos peritos forenses.

As entrevistas foram gravadas em suporte áudio. No final das mesmas solicitávamos o preenchimento de uma ficha sociodemográfica para uma caraterização dos participantes. Em média, as entrevistas duraram 45 minutos e cada transcrição preencheu cerca de 10 páginas de texto.

\section{Tratamento dos dados}

Atendendo à natureza qualitativa da temática em estudo, recorremos à utilização de um modelo de investigação que se pauta por uma "lógica exploratória, como um meio de descoberta e de construção de um esquema teórico de inteligibilidade, e não tanto numa ótica de verificação ou de um teste de uma teoria ou hipóteses preexistentes" (Maroy, 1997, p. 117).

De entre as opções de cariz qualitativo, no tratamento das entrevistas optámos pela análise de conteúdo temática, um método de análise indutivo, em que o "tema é a unidade de significação que se liberta naturalmente de um texto analisado segundo critérios relativos à teoria que serve de guia à leitura" (Bardin, 1977, p.105)

0 tratamento das entrevistas foi processado através de um suporte informático - programa Nvivo 
(versão8) - que permitiu uma estratégia sistemática de codificação das entrevistas. Importa ainda referir que a unidade de registo utilizada foi a frase e que as codificações foram revistas por um outro codificador, a co-autora deste trabalho.

\section{RESULTADOS}

Da análise efetuada às entrevistas, surgiram os seguintes temas: Posição face ao conceito "superior interesse da criança"; Motivo para o pedido pericial; Tipo de informação solicitada aos peritos; Qualidade da perícia; Parâmetros de uma perícia esclarecedora; Expectativas face à direção da perícia; Adequação da perícia; Postura face a situações problemáticas; Credibilidade da perícia; Relevância da perícia psicológica; Relevância da conclusão; Referências à perícia na sentença; Divergência entre perícia e sentença; 0 testemunho do perito em tribunal; Sugestões e recomendações. Cada um destes temas será explanado em seguida.

\section{Posição face ao conceito "superior interesse da criança"}

O superior interesse da criança é, para todos os participantes, um conceito indeterminado (e.g., "isso é praticamente, é quase impossível de definir..."(E1) ; "às vezes as pessoas ficam um bocadinho perplexas com os nossos conceitos indeterminados, mas eu acho que às vezes também tentar reduzi-los ou definir é redutor..."- E3), abstracto (e.g., "o interesse do menor realmente pode ser interpretado de uma forma muito ampla"- E8), casuístico (e.g., vai adoptando um conteúdo variável, de acordo com as situações a que se aplica" (E5); "Há situações em que o conceito justifica que se invista muito na família, de alguma forma, recuperar aquela família para inserir a criança no seu contexto familiar, há outras situações que revelam outra vertente, a do afastamento dos pais, para uma instituição ou adopção" - E6) e mutável (e.g., estamos a falar de um conceito em constante mutação e que dá azo a essa mutabilidade e variedade de conteúdo" E2).

Uma das definições avançadas integra todos esses elementos caraterizadores do conceito: " $o$ superior interesse da criança terá que ser perspectivado, independentemente dos conceitos que cada um dá de si, na perspectiva do que é melhor para a criança. E o melhor, a todos os níveis, começando necessariamente por aquilo que são as necessidades básicas de qualquer ser humano, alimentar, de saúde, de higiene, de uma escola, aquilo a que qualquer ser humano tem direito a ter desde que nasce até morrer. $E$ depois, a sua parte emocional e afectiva, ninguém vive sem afectos, ninguém vive sem o equilíbrio emocional, sem felicidade, sem amor, sem amizade, sem laços afectivos estruturados, sejam eles com os pais biológicos, com famílias de acolhimento ou com famílias adoptivas. Tudo o que seja uma decisão que responda a estas necessidades responde ao interesse do menor. É uma perspectiva necessariamente, e tem que ser, egoísta, perspectivada única e exclusivamente nos olhos da criança" (E7).

Apesar da variabilidade supracitada, relativamente à criança, foi referido que o objetivo será proporcionar-lhe um ambiente familiar estável promotor de um desenvolvimento salutar ( $\mathrm{N}=3$ ), o que engloba a manutenção da "relação com a pessoa com quem o menor tem uma relação mais forte, mas também o de manter, dentro do possível, e o mais possível, o contacto com o progenitor que não tenha a guarda" (E5), bem como a idade da criança $(\mathrm{N}=1)$ e a sua proteção $(\mathrm{N}=1)$. No que concerne aos pais, foi destacada a postura $(\mathrm{N}=1)$ que adotavam em relação ao menor e o comportamento em relação ao progenitor não custódio, nomeadamente na facilitação dos contactos com o filho $(\mathrm{N}=2)$.

\section{Motivo para o pedido pericial}

Na perspetiva dos participantes, os motivos que maioritariamente presidem ao pedido pericial são: a postura litigante dos pais no processo $(\mathrm{N}=3$; e.g., desacordo no tipo de guarda e regime de visitas; manipulação do menor); alegações de abuso sexual ou maltrato $(\mathrm{N}=4)$; questões relativas ao (des)ajustamento dos pais (e.g., problemas de consumo de substâncias ( $\mathrm{N}=1$ ), necessidade de avaliação da personalidade $(\mathrm{N}=1)$, capacidades parentais $(\mathrm{N}=1)$, alterações na criança (alterações comportamentais $(\mathrm{N}=1)$, tais como a recusa do contacto em relação ao progenitor não custódio $(\mathrm{N}=2)$, e, por fim, situações complexas e ambíguas (e.g., "quando ultrapassa a normalidade" ( $\mathrm{N}=3$ ), "a nossa capacidade" ( $\mathrm{N}=2$ ) ou quando há indicação dessa necessidade por outros técnicos (e.g., quando "o relatório social indica"; $\mathrm{N}=1$ ).

É de salientar a intervenção dos advogados para que o pedido pericial tenha lugar, uma vez que à exceção de um juiz, todos consideram que aqueles têm um papel muito interventivo nestes processos. De resto, os advogados são apontados na maioria dos casos como tendo a iniciativa de pedir a perícia $(\mathrm{N}=6)$.

A decisão de não solicitar a perícia é sustentada pelos magistrados com base no princípio da intervenção mínima $(\mathrm{N}=2)$, a irrelevância para o processo $(\mathrm{N}=2)$, o atraso $(\mathrm{N}=1)$ e o encarecimento do processo $(\mathrm{N}=1)$, a ausência de impacto do conflito na criança $(\mathrm{N}=1)$ e, ainda, um eventual acordo entre as partes $(\mathrm{N}=1)$. 


\section{Tipo de informação solicitada aos peritos}

Face aos peritos, os magistrados reportam a formulação de pedidos genéricos (N=5) e/ou casuísticos (i.e., em função do caso em concreto; $\mathrm{N}=3$ ).

Além disso, referiram os pedidos de avaliação relativos às relações pais-filhos ( $\mathrm{N}=5$; e.g., informação sobre a dinâmica familiar, sobre a relação do menor com os progenitores, sobre as capacidades parentais), da avaliação da manipulação do menor ( $\mathrm{N}=3)$, da credibilidade relativa às alegações abuso sexual $(\mathrm{N}=3)$, da personalidade do menor e progenitores $(\mathrm{N}=2)$ e do grau de maturidade do menor $(\mathrm{N}=1)$.

\section{Qualidade da perícia}

Relativamente à apreciação da qualidade da perícia, os magistrados usaram critérios relativos à perícia per si, critérios por contraste (comparando documentos ou perícias executadas por diferentes instituições ou institutos) e por variabilidade entre as perícias. Per si destaca-se a fundamentação sólida ( $\mathrm{N}=4)$, a objetividade $(\mathrm{N}=1)$ e o facto de as perícias executadas serem esclarecedoras $(\mathrm{N}=1)$. Por contraste, face a outros documentos, verbalizaram que, face à superficialidade dos relatórios sociais, sobressaem nas perícias psicológicas a exaustividade $(\mathrm{N}=4)$ e a utilidade $(\mathrm{N}=2)$. Ainda dentro desta categoria, constatouse que a instituição executora da perícia é relevante $(\mathrm{N}=1)$, nomeadamente quando se trata de uma entidade pública $(\mathrm{N}=1)$. Alguns participantes destacaram em concreto $(\mathrm{N}=4)$ a qualidade das perícias psicológicas da Universidade do Minho, salientado a sua utilidade, exaustividade, fundamentação e objetividade.

Os magistrados não deixaram, contudo, de acentuar a variabilidade que subsiste entre diferentes perícias ( $\mathrm{N}=4)$, com referências a relatórios díspares e com diferentes graus de utilidade e qualidade (e.g., "depende, há perícias psicológicas que não ajudam muito, às vezes são demasiado extensas, com conceitos demasiado técnicos, que são difíceis de perceber e há outras que são mais simples, têm também esses conceitos mas são traduzidos, explicados" - E6).

\section{Parâmetros de uma perícia esclarecedora}

Para os magistrados, são vários os parâmetros que tornam uma perícia esclarecedora. A maioria destacou a metodologia ( $\mathrm{N}=8$; e.g., boas e relevantes fontes, múltiplas metodologias, instrumentos que possibilitam a compreensão do relatório e das conclusões que o perito alcançou). Outros parâmetros valorizados foram: a acessibilidade da linguagem ( $\mathrm{N}=5$; "tem que ser uma linguagem que sem deixar de ser técnica, tem que ser um linguagem acessível aos destinatários" - E2), a celeridade (N=5; "penso que a brevidade é um factor fulcral neste tipo de processo, tal como eu os vejo, e penso que a maior parte dos magistrados que têm cuidado com a jurisdição de menores exige sessões que sem ser precipitadas, em tempo útil, têm de ser necessariamente rápidas" - E7) e a extensão adequada da perícia (N=3). De forma mais idiossincrática, foi referenciada a clareza do relatório pericial $(\mathrm{N}=1)$ e a compreensibilidade da conclusão $(\mathrm{N}=1)$. Foi igualmente destacado nos seus discursos a ausência de parâmetros pré-definidos (N=2; e.g., "critérios não há, a lei sugere-nos que solicitemos relatórios a entidades públicas, mas não há nenhum critério predefinido" - E1).

\section{Expectativas face à direção da perícia}

A maioria dos magistrados esperava da perícia psicológica uma sugestão para a resolução do conflito (N=7; e.g., "que expresse uma opinião, um caminho, tem que ser de alguma forma conclusiva ou não ser conclusiva mas assumindo que por este ou aquele motivo não se chegou a conclusão nenhuma" - E10), a par de uma ilustração das relações familiares (N=3; e.g., "o que eu espero de facto é que surja ali um esclarecimento do que é que se passa entre aqueles progenitores, aquela criança, qual é a relação que tem com um, com o outro, de que forma é que encaram o exercício do poder parental, como é que são as relações entre ambos, se continua a haver um litígio muito grande, se sabem pôr de parte o litígio que têm entre si e sobrepor o interesse da criança, enfim, no fundo é mais isso, é uma avaliação da situação de facto que existe" - E5).

Apenas um dos participantes referiu que a ausência de expectativas concretas, as quais são formuladas consoante o caso.

\section{Adequação da perícia}

A este nível os entrevistados partilharam diferentes perceções. Para quatro dos magistrados habitualmente a perícia responde ao que é esperado, ou seja, "a resposta bate certo, entre aspas, responde aquilo que é perguntado" (E2). Por vezes, a perícia oferece apenas uma resposta possível (N=3; e.g., "eu imagino que quando não nos dizem o que nós queremos, eu imagino que seja porque não é uma ciência exacta, lá está, não vale a pena, se pudesse ser às cruzes, era o ideal, mas não pode" - E4). Dois magistrados 
admitiram que a perícia pode ser inconclusiva face ao solicitado (e.g., "às vezes, de facto, é inconclusiva" E1).

Foi salientada por dois magistrados a dificuldade associada à peritagem que envolve simultaneamente alegações de abuso sexual (e.g., "eu acho que as perícias na área das crianças, de suspeitas de abuso sexual, são sempre complicadas, quanto mais, se calhar não quanto mais pequenos forem mas, acho que depende da idade, e acho que são sempre complicadas, não havendo sinais físicos que possam depois ajudar, eu acho que são sempre muito complicadas essas perícias, porque têm sempre muito a ver com o que elas verbalizam. São as que me suscitam mais reservas" - E10).

\section{Postura face a situações problemáticas}

Os entrevistados foram questionados sobre qual é a sua prática face a dois cenários algo comuns existência de diferentes perícias e progenitores em condições equitativas - uma vez que estas condições poderão ser geradoras de maior ambiguidade.

A possibilidade de se ser confrontado com relatórios ou perícias em sentidos diferentes é tida, por alguns entrevistados, como uma situação rara em processos de RRP (N=3; e.g., "não é assim tão frequente, pelo contrário, é quase excepção termos relatórios que apontem, podem dizer coisas ligeiramente diferentes, mas apontar em sentidos diferentes é muito raro" - E1). Se tal acontecer, são diversas as estratégias a que os magistrados recorrem, a saber: - avaliação da totalidade da prova ( $\mathrm{N}=4$; e.g., "é tudo ponderado, são analisados todos os documentos juntos e são analisados. As próprias pessoas em si são avaliadas, em todas as diligências que nós temos nós vamos conhecendo as pessoas, conhecendo as crianças, o modo de ser delas, a personalidade delas, tudo isso é valorado" - E6); - pedido de nova perícia ( $\mathrm{N}=2$; e.g., "se visse a criança e o relatório me parecesse completamente contrário" - E4); - atender fundamentalmente às finalidades de cada perícia ( $\mathrm{N}=2$; e.g., "as perícias não tem necessariamente que se sobrepor umas às outras, cada uma dentro da sua área. Nessa medida vamos lá ver, dentro da sua área e consoante aquilo que estiver em causa. Se estivesse em causa aferir uma questão mais de índole médica, digamos assim, aí podia dar prevalência à perícia médica. Se fosse mais uma questão de índole psicológica, de grau de maturidade, de desenvolvimento, aí eventualmente daria mais à psicológica. Mas quer dizer, na medida do possível, há que tentar harmonizálas a todas para se tentar aproveitar o máximo de todas, porque se as solicitamos, é porque achamos que eram pertinentes" - E2); - avaliação da fundamentação do relatório ( $\mathrm{N}=1$; e.g., "uma perícia estar melhor fundamentada do que outra, ou ser mais coerente que outra" - E3); - intuição do juiz (N=3; e.g., "a nossa própria experiência pessoal, as nossas próprias convicções, tudo isso, depois no momento da decisão é relevante"- E6) e, por fim, pedido de esclarecimentos da perícia ( $\mathrm{N}=1$; e.g., "aí eu muitas vezes peço esclarecimentos, em função deste e deste elemento, porque às vezes podem estar a dizer a mesma coisa mas sob vertentes diferentes e podem-se complementar"- E6).

Face à eventualidade de pai e mãe se encontrarem em condições equitativas, os magistrados atendem às caraterísticas da criança $(\mathrm{N}=3)$, às caraterísticas dos pais $(\mathrm{N}=3)$, à (manutenção da) situação anterior $(\mathrm{N}=2)$, ao caso concreto $(\mathrm{N}=2)$, à atribuição da guarda conjunta $(\mathrm{N}=1)$ ou ao acordo das partes $(\mathrm{N}=1)$.

As caraterísticas da criança que podem ajudar os magistrados a decidir sobre a guarda são a sua vontade expressa, a tenra idade (nesse caso por norma a guarda seria atribuída à mãe) e a "manutenção da relação com quem o menor tiver uma ligação mais próxima, ver qual é o cônjuge que é a figura de referência daquele menor" (E5).

De entre as caraterísticas dos pais que facilitem uma decisão quanto à guarda, destacaram a figura do cuidador principal e o progenitor que facilitasse o contacto com o progenitor não custódio e com a respetiva família alargada.

A manutenção da situação anterior da criança também se apresentou como solução, se esta se apresentar adequada (e.g., "vou pela situação instalada, digamos, pelo que a criança já vivenciou" - E3).

Os participantes reforçaram ainda a necessidade da avaliação do caso concreto (e.g., "aí só analisando o caso concreto, com os dados mais ou menos probatórios" - E2); a possibilidade da guarda conjunta (e.g., "se tiver numa situação dessas, o ideal é a guarda conjunta, à partida" - E5) e, por fim, o acordo das partes (e.g., "é muito mais complicado, a não ser que por acordo eles se entendam" - E6).

\section{Credibilidade da perícia}

Uma perícia torna-se mais credível em função de quem a executa $(\mathrm{N}=5)$, do recurso a metodologias múltiplas ( $\mathrm{N}=4$; e.g., uma vez que "quanto mais contextos possam transparecer do relatório melhor, porque mais garantias me dá de que as conclusões a que o técnico chegou estarão mais perto da realidade" - E9), da qualidade da sua fundamentação $(\mathrm{N}=2)$ e da coerência com a restante prova $(\mathrm{N}=1)$.

Relativamente ao executor da perícia, os magistrados sublinham o peso das entidades públicas sobre as privadas (e.g., "quando muitas vezes há um confronto entre a perícia privada e a pública, em regra, 
daria mais prevalência à segunda, aquela solicitada à entidade pública. A partir do momento em que eu peço uma perícia a uma entidade pública, obviamente que tenho que partir da presunção que é uma perícia fidedigna" - E2), a idoneidade dos peritos (e.g., "é sempre menos credível uma perícia que é pedida particularmente por uma das partes. Não é tanto a idoneidade profissional da pessoa ou da própria perícia, que até pode ser um relatório muito bem feito e muito convincente, mas não tem o mesmo valor porque não nasce nas mesmas condições de imparcialidade" - E7) e o "bom nome" da entidade executora (e.g., "os pareceres merecem-me credibilidade pela qualidade que têm, pela isenção que têm e pela ciência que eu acho que as pessoas têm, pelas rubricas de quem assina" - E7).

\section{Relevância da perícia psicológica}

Todos os participantes, de modo consensual, reportam a perícia psicológica como um instrumento de trabalho muito importante e com um papel fulcral na formação da convicção do julgador (e.g., "o trabalho que se vê num relatório auxilia-nos, ajuda-nos, serve de elemento até para o convencimento das partes, de tratamento melhor da questão" - E7).

Esse papel de relevo da perícia acaba por se refletir, na perspetiva dos entrevistados, na concordância entre a perícia e a sentença (N=3; e.g., "normalmente a decisão vai de encontro ao que é descrito no relatório, mesmo o relatório não apontando a decisão, dispõe de matéria que nos leva a confiar" - E1).

\section{Relevância da conclusão}

De acordo com todos os participantes, a conclusão assume relevância igual ou inferior quando comparada com as restantes partes do relatório (e.g., "há determinados pontos que são referidos na fundamentação ou na exposição, que são tão ou mais importantes do que a conclusão. Ou seja, na conclusão podemos destacar um ou outro ponto, só que há pontos na fundamentação que de facto são essenciais para nós" - E2).

\section{Referências à perícia na sentença}

A localização das referências da perícia na sentença suscitou respostas diferentes. Assim, alguns participantes partilharam opções claras: dois participantes referiram preferir situá-las na secção da motivação, um outro na secção dos factos provados e o outro, por sua vez, na secção do relatório. De salientar que os restantes apenas mencionaram que lhe fazem referência, mas não o local específico em que o fazem $(\mathrm{N}=3)$. Face à eventualidade de não existirem referências à perícia na sentença, alguns participantes avançaram algumas hipóteses explicativas para essa ausência: diferentes métodos de trabalho ( $\mathrm{N}=4$; e.g., "depende da forma como os magistrados trabalham" - E6); ter sido desnecessária $(\mathrm{N}=3)$ para a questão em discussão (e.g., "se calhar não trouxe nada de novo, não acrescentou" - E3) e o uso de linguagem técnica $(\mathrm{N}=1$; "eu nunca transcreveria uma coisa muito técnica, porque não vale a pena, porque aquilo não é para um livro, não é?” - E4).

\section{Divergência entre perícia e sentença}

Dois dos participantes consideraram raro existir divergência entre a perícia e a sentença. De entre os possíveis motivos para essa desarmonia foram referidos: o desacordo com o resto da prova $(\mathrm{N}=4)$; a existência de um outro parecer "melhor" (N=3); o facto de a avaliação estar desatualizada (N=3); a evidência de pressupostos incorretos do perito $(\mathrm{N}=3)$, quer ao nível das premissas em que se baseia o relatório, quer ao tentar ir de encontro ao que julga ser a opinião do magistrado sobre o desfecho do processo; a ausência de fundamentação $(\mathrm{N}=1)$; a existência de uma solução inexequível proposta pelo perito $(\mathrm{N}=1)$; perceções diferentes entre juiz e técnico $(\mathrm{N}=1)$ no que diz respeito às partes e, por fim, a existência de o acordo das partes $(\mathrm{N}=1)$ num outro sentido.

\section{0 testemunho do perito em tribunal}

A maioria dos magistrados $(\mathrm{N}=7)$ considerou incomum chamar o perito para testemunhar em tribunal. No caso de suceder, tal poderá ser motivado por um pedido de esclarecimentos $(\mathrm{N}=6)$ acerca de alguma questão que levantasse dúvidas, por pedido das partes $(\mathrm{N}=5)$ ou, ainda, pelo surgimento de novos dados $(\mathrm{N}=1)$ no período pós-perícia.

\section{Sugestões e recomendações}

De entre as sugestões partilhadas pelos magistrados ao nível da RRP destaca-se a necessidade de colocação de psicólogos nos tribunais $(\mathrm{N}=4)$. Foi ainda sugerida a mediação familiar $(\mathrm{N}=2)$, a necessidade de ações de formação dos magistrados na área da psicologia $(\mathrm{N}=2)$, a colocação de mais técnicos no terreno $(\mathrm{N}=1)$ e a maior especialização dos tribunais $(\mathrm{N}=1)$.

No que respeita às perícias, os magistrados avançaram, essencialmente, recomendações de cariz 
metodológico ( $\mathrm{N}=5$; e.g., referir as fontes, a acessibilidade da linguagem, uma fundamentação sólida, a multidisciplinaridade das áreas envolvidas nos processos de RRP), de conteúdo (N=3; e.g., maior poder de síntese, a apresentação de uma solução para o desfecho do processo) mas também éticas (N=1; e.g., "é que façam exactamente aquilo que acham que é mais correcto e que não se preocupem em ser eles a resolver o problema do juiz" - E9).

Como crítica construtiva surgiu a maior especialização das áreas de saber $(\mathrm{N}=1)$ e um consequente trabalho de maior qualidade dos profissionais da psicologia forense. Como insuficiências ou limitações foi reportada a demora no envio dos relatórios periciais $(\mathrm{N}=3)$, o uso de linguagem técnica $(\mathrm{N}=3)$, a ausência de fundamentação de alguns relatórios $(\mathrm{N}=1)$, a excessiva extensão $(\mathrm{N}=1)$ e, ainda, a pouca transparência dos executores (N=1; e.g., "agora há uma coisa que às vezes me criava alguma preocupação, que era o facto de o tribunal solicitar a intervenção de alguns Organismos e constatar que por vezes esse mesmo Organismo presta serviços privados às próprias partes e isso abala um bocadinho, digamos assim, a imparcialidade do serviço"- E6).

\section{DISCUSSÃo}

A realização deste estudo permitiu-nos conhecer melhor a valoração que os magistrados fazem da atividade pericial e, especificamente, o impacto dessa prática na decisão judicial.

0 domínio da RRP revela-se intrincado, principalmente pelo impacto que causa entre os intervenientes, quer sejam os progenitores, os menores, os próprios magistrados e/ou os peritos envolvidos. De há uns anos a esta parte que a lei (art. 655.ํ, C.P.C., 2007) oferece aos magistrados a opção de se socorrerem de outras ciências na altura de decidir. Apesar de não serem vinculativos, assiste-se a um aumento exponencial de pedidos de avaliação psicológica forense. Embora essa evolução nos pareça positiva, o facto é que na maior parte dos processos de RRP não há lugar a pedido pericial. Esta evidência, de acordo com os magistrados, advém de, em grande parte dos conflitos em RRP, a resolução ser encontrada por acordo entre os progenitores.

$\mathrm{Na}$ perspetiva dos magistrados, a perícia psicológica deve ser solicitada quando se registam alterações na criança, quando há dúvidas sobre a (des)adequação da postura dos pais ou quando os magistrados têm em mãos situações particularmente complexas. Estes motivos, de resto, vão ao encontro das áreas que, habitualmente, se entende que devem ser avaliadas neste tipo de processos: a capacidade parental dos progenitores; o seu ajustamento psicológico e a sua capacidade para supressão das necessidades do(s) menor(es); a interacção do(s) menor(es) com os progenitores; bem como, a possibilidade de existência de condutas inapropriadas que possam influenciar o bom desenvolvimento do(s) menor(es) (e.g., Antunes et al., 2005; Pereira \& Matos, 2011). Assim, ainda que a lei não determine as situações em que devem solicitar a perícia, parece haver entre aos magistrados critérios bastante unânimes e demarcados para o fazer.

Ainda que a perícia não tenha um carácter vinculativo e não seja uma constante nos processos de RRP, constatámos que esta se constitui um elemento fundamental para auxiliar a decisão final dos magistrados entrevistados. Isto porque todos os participantes consideraram a perícia como um instrumento de trabalho muito importante, com um papel fulcral na formação da convicção do julgador.

Um outro aspeto alvo de destaque, relaciona-se com o facto de os magistrados se socorrerem, nas suas decisões, das várias partes constituintes da própria perícia, concedendo-lhes importância idêntica. Esta evidência vem desafiar o mito algo comum de que somente a conclusão das perícias seria alvo de atenção por parte dos seus destinatários. De facto, os magistrados, não negando que esperam ver reflectida na conclusão da perícia uma solução para o problema ou pelo menos uma orientação nesse sentido, revelam igualmente que a informação que lhes permite apoiar a sua decisão e que lhes ilustra as relações familiares consta na fundamentação da perícia.

Tendo em conta a não obrigatoriedade de formular quesitos (art. 557.ำ, C.P.C., 1999), apesar de os magistrados admitirem que às vezes fazem pedidos genéricos, observa-se igualmente um esforço crescente por parte daqueles de especificar os seus pedidos e tomar conhecimento das relações que se estabelecem no seio de cada família. Desta forma, denota-se uma mudança, em comparação com a noção fornecida pela literatura de que os pedidos judiciais se focam, maioritariamente, nas competências individuais e no ajustamento psicológico dos progenitores (Antunes et al., 2005).

A perícia psicologia, além de per si se apresentar como um instrumento de trabalho bastante relevante, distingue-se dos relatórios sociais, pela sua utilidade e extensão. Além disso, de acordo com os magistrados, a resposta da perícia à informação solicitada revela-se, na maior parte das vezes, adequada. Porém, não desprezam a dificuldade associada aos casos de abuso sexual, casos em que a própria investigação empírica e literatura da especialidade documentam a complexidade que as alegações de abuso acarretam ao processo, quer para as partes, quer para os técnicos (Bow, Quinnell, Zaroff, \& Assemany, 2002; Ribeiro, 2006). 
Dado que os magistrados entendem que a perícia é habitualmente um instrumento útil e que, por norma, esta responde à informação pretendida, tal poderá ajudar a compreender a reduzida frequência com que os peritos são chamados a tribunal. Um dos motivos que levaria um magistrado a chamar um perito a tribunal seria o pedido de esclarecimentos mas, embora o art. 588. (C.P.C., 2007) proporcione aos magistrados a possibilidade de pedirem a comparência dos peritos na audiência final, constata-se que esta não é uma prática comum tal como avançaram os participantes, à semelhança aliás dos dados avançados por outros estudos (e.g., Gudjonsson \& Haward, 1998; Machado \& Matos, 2008): apenas em $2 \%$ e $7,7 \%$ dos casos, respetivamente, o psicólogo era chamado a testemunhar.

Relativamente aos elementos que tornam uma perícia mais credível, destaca-se a entidade executora e o recurso a múltiplas metodologias. Se, por um lado, a importância concedida às credenciais da entidade executante e do respetivo perito vão de encontro aos resultados encontrados noutros estudos (e.g., Bornstein, 2004), por outro, a importância concedida pelos magistrados à utilização de múltiplas metodologias revela-se um elemento adicional. Na verdade, a metodologia utilizada nas perícias mereceu de novo destaque no discurso acerca do que é uma perícia esclarecedora. Paralelamente, a acessibilidade da linguagem e a celeridade foram também valorizados pelos magistrados. De resto, a clareza da linguagem aparece na literatura como um dos aspetos a que os peritos têm de ter mais atenção (e.g., Ackerman, 2006). Por outro lado, e tendo em conta os principais alvos da RRP - os menores, compreende-se a importância da celeridade na perícia, atendendo ao superior interesse da criança.

A este respeito, importa igualmente refletir sobre este conceito indeterminado. A intenção do legislador de conceder ao magistrado flexibilidade na aplicação deste conceito ao caso concreto é bem recebida por estes. Porém, o critério que rege o futuro de tantas crianças não deveria ser algo mais claro, que valorasse menos a sensibilidade pessoal e subjetiva do decisor? Têm surgido várias vozes nesse sentido que defendem, à semelhança, por exemplo, da legislação inglesa, a adoção de uma lista de critérios que o juiz, mais objetivamente, teria de considerar e pesar na sua decisão (Emery, 1994; Krauss \& Sales, 2000; Simões et al., 2006; Sottomayor, 2004). Na prática, esta alternativa traria menos dificuldade ao decisor na hora de salvaguardar o menor e decidir quanto à guarda, o que transformaria a decisão do tribunal menos arbitrária, baseada em critérios mais claros. 0 magistrado continuaria protegido pela discricionariedade, pois ao elencar mais objetivamente os critérios poderia ficar em aberto o valor que cada um teria e, em caso de conflito, seria o próprio magistrado a atribuir-lhe o valor que entendesse atendendo ao caso concreto.

Outro resultado analisado foi a postura adoptada pelos magistrados face a situações problemáticas algo comuns: peso de diferentes relatórios e posição equitativa do pai e da mãe em termos de parentalidade adequada. Relativamente ao peso de diferentes relatórios, a literatura refere que comparando as perícias psicológicas com as perícias médicas, se observa uma tendência para conferir maior peso às segundas, já que a credibilidade é influenciada diretamente pelo nível de cientificidade (Bruce, 2001). Em processos de RRP, no entanto, a evidência de relatórios em sentidos diferentes revelou-se incomum. No caso de os pareceres ou perícias se revelarem contraditórios, os magistrados socorrem-se de estratégias tais como: avaliação da totalidade da prova; pedido de nova perícia; atender às finalidades de cada perícia; avaliação da fundamentação do relatório; intuição e, por fim, pedido de esclarecimentos acerca da perícia. Por outro lado, na situação de terem dois progenitores em condições similares, apenas um juiz referiu que nesse caso a melhor situação era a guarda conjunta. Nesta situação, os magistrados referem atender às caraterísticas da criança e dos pais, à manutenção da situação anterior, ao caso concreto ou ao acordo das partes. No entanto, esta evidência pode denotar que, a esse nível, há assim um longo caminho a percorrer de forma a acompanhar a evolução sociológica e legislativa operada no nosso país que se traduz em novas formas de família e novas formas de viver a conjugalidade e a parentalidade. De facto, a família moderna, por vezes demarcada por divórcios e posteriores reorganizações familiares, dá origem a novos modos de exercer a parentalidade (co-parentalidade, monoparentalidade; Kreeger, 2003; Relvas \& Alarcão, 2002).

Um aspeto menos esperado que se destaca neste estudo é a forma como a perícia objetivamente se reflete na sentença. Ainda que o art. 659. (C.P.C., 2007) refira a estrutura que as sentenças devem seguir, na realidade percebemos que não existia unanimidade entre os magistrados no que respeita ao recurso à perícia na sentença e que os procedimentos variam consoante o juiz que conduz o processo.

Por fim, ainda que os magistrados reconheçam que as alterações efetuadas ao nível da terminologia nos últimos anos acompanhem a evolução social, e lhe reconheçam a vantagem de facilitar a comunicação com os intervenientes, não são essas as alterações mais valorizadas pelos magistrados, privilegiando outras alterações efetivas, tais como o investimento a nível da alocação de mais técnicos para avaliar a situação familiar e/ou lares e famílias de acolhimento. Os magistrados destacaram ainda a necessidade de colocação de psicólogos nos tribunais, a mediação familiar, a oferta de ações de formação aos magistrados na área da psicologia e a colocação de mais técnicos no terreno. Estes resultados 
reforçam, uma vez mais, a sua abertura à Psicologia e à importância que lhe concedem neste tipo de processos.

\section{CONCLUSÃO}

Uma das conclusões centrais deste trabalho é que a perícia psicológica se assume como um importante instrumento de apoio na decisão judicial. Além disso, os magistrados, no cômputo geral, manifestaram-se muito satisfeitos com a prática pericial, nomeadamente com a objetividade, exaustividade e fundamentação das mesmas. Apelaram, contudo, para uma maior celeridade na emissão da mesma e para os cuidados a ter com a linguagem, uma vez que eles não são os únicos destinatários da perícia. Constatámos, assim, uma efetiva aproximação entre a Psicologia e o Direito.

Quanto às limitações do estudo, é de referir o facto da amostra se ter cingido a magistrados que anteriormente tinham solicitado perícias à Universidade do Minho. Não obstante estes magistrados terem contacto com perícias procedentes de outras entidades, esta situação poderá ter limitado os dados. Por outro lado, o universo de participantes $(\mathrm{N}=10)$ pode ser ampliado, de forma a reforçar os dados obtidos. É ainda de salientar que a escassez de estudos empíricos neste domínio não permitiu uma discussão dos resultados mais ampla. Contudo, com este trabalho esperamos ter contribuído para refletir e aperfeiçoar o desempenho dos peritos, no sentido destes melhor auxiliarem o poder judicial ao identificarem as áreas que conferem à perícia maior qualidade.

Por fim, a RRP é uma área que enfrenta ainda inúmeros desafios, havendo ainda questões que ficam em aberto, podendo constituir foco de análise em estudos posteriores. A título de exemplo, destacamos o interesse de avaliar as práticas dos psicólogos no nosso país, no sentido de perceber se as guidelines existentes são de facto seguidas e quais os aspetos que poderiam ser melhorados.

\section{Referências}

Ackerman, M. (1995). Clinician's guide to child custody evaluations. New York: John Wiley \& Sons.

Ackerman, M. (1999). Essentials of forensic psychological assessment. New York: John Wiley \& Sons.

Ackerman, M. (2006). Forensic Report Writing. Journal of clinical psychology, 62, 59-72. doi: 10.1002/jclp.20200

Antunes C., Caridade, S., \& Pereira, A. (2005). Avaliação dos processos de regulação do poder paternal. In Gonçalves, R. A., \& Machado, C.(Coords.), Psicologia Forense (pp. 289-317). Coimbra: Quarteto Editora.

Bardin, L. (2004). Análise de conteúdo. Lisboa: Edições setenta.

Bardin, L. (1977). Análise de conteúdo. Lisboa: Edições setenta.

Bornstein, M. (2004). The impact of different types of expert scientific testimony on mock jurors liability verdicts in psychology. Crime \& Law, December, 10, 429-446. doi: $10.1080 / 1068316030001629292$

Bow, J., \& Quinnell, F. (2001). Psychologists current practices and procedures in child custody evaluations: five years after American Psychological Association guidelines. Professional Psychology: Research and Practice, 32, 261-268. doi: 10.1037/0735-7028.32.3.261

Bow, J, Quinnell A., Zaroff, M., \& Assemany, A. (2002). Assessment of sexual abuse allegations in child custody cases. Professional Psychology: Research and Practice, 33, 566-575. doi: 10.1037/07357028.33.6.566

Bricklin, B. (1995). The custody evaluation handbook: research-based solutions and applications. New York: Brunner/Mazel, inc.

Bruce, D., Daniel, A., Krauss, D., \& Sales, B. (2001). The effect of clinical and scientific expert testimony on juror decision making in capital sentencing. Psychology, Public Policy and Law, 7, 267-210. doi: 10.1037/1076-8971.7.2.267

Charlish A. (1997). Apanhados no meio: ajudar as crianças a enfrentarem a separação e o divórcio. Porto: Âmbar.

Caridade, S., Machado, C., \& Gonçalves R. (2008). Unidade de Consulta em Psicologia da Justiça: da avaliação à intervenção. In Taveira, M., \& Silvério, J. (2008). Intervenção psicológica no ensino superior (pp. 102-115). Serviço de Consulta em Psicologia e Desenvolvimento Humano, Instituto de Educação e Psicologia: Universidade do Minho.

Catalán, M., Garcia, M., Alemán, C., Andréu, P., Esquiva, A., Garcia, M., Marín, C., Matás, A., \& Soler, C. (2008). Custodia compartida: Solicitudes de esta modalidad de custodia en procedimientos amistosos y contenciosos, desde la entrada em vigor de la nueva ley de divorcio (15/05). In Rodríguez, F., Bringas, C., Fãrina, F., Arce, R. \& Bernardo, A. (Eds.). Psicología Jurídica: Familia y Victomología. Colección Psicología y Ley, no6 (pp.123-129). Sociedade Española de Psicología Jurídica y Forense. 
Código de Processo Civil (2007). Coimbra: Almedina.

Código Processo Civil anotado (1999). Coimbra: Almedina.

Correia, C. (2008). Regulação do exercício do poder paternal: Caracterização das famílias em litígio e da prática pericial. Tese de mestrado em Psicologia na especialidade de justiça. Braga: Universidade do Minho.

Direçao-Geral da Política da Justiça (2014). Estatísticas da Justiça. Retirado de http://www.siej.dgpj.mj.pt/webeis/index.jsp?username=Publico\&pgmWindowName=pgmWindo w_635712726213593750

Delgado, P. (1996). Divórcio e separação em Portugal: análise social e demográfica, século XX. Cidade: Editora.

Emery, R. (1994). Renegotiation family relationships: divorce, child custody, and mediation. New York: The Guilford Press.

Fariña, F., Arce, R., Seijo, D., \& Novo, M. (2002). Psicología jurídica de la familia. Intervención en casos de separación y divórcio. Barcelona: Cedecs Editorial S.L.

Gonçalves, R. (2010). Psicologia Forense em Portugal: Uma história de responsabilidades e desafíos. Análise Psicológica, 1, 107-115.

Gudjonsson, G., \& Haward, G. (1998). Forensic Psychology: A guide to practice. Routledge: London \& New York.

Instituto Nacional de Estatística (INE) (2009). Estatísticas Demográficas 2009. Lisboa: INE.

Instituto Nacional de Estatística (INE) (2015). Retirado de https://www.ine.pt/xportal/xmain?xpid=INE\&xpgid=ine_indicadores\&indOcorrCod=0008132\&co ntexto=bd\&selTab=tab2

Krauss, D., \& Sales, B. (2000). Legal standards, expertise, and experts in the resolution of contested child custody cases. Psychology, Public Policy, and Law, 6, 843-879. doi: 10.1037//1076-8971.6.4.843

Kreeger, J. (2003). Family psychology and family law - a family court judge's perspective: comment on the special issue. Journal of Family Psychology, 17, 260-262. doi: 10.1037/0893-3200.17.2.260

Kruk, E. (2011). A model equal parental responsibility presumption in contested child custody. The American Journal of Family Therapy, 39, 375-389. doi: 10.1080/01926187.2011.575341

Manita, C., \& Machado, C. (2012). A Psicologia Forense em Portugal - novos rumos na consolidação da relação com o sistema de justiça. Análise Psicológica, 1-2, 15-32.

Maroy, C (1997). A análise qualitativa de entrevistas. In Albarelllo, L., Digneffe, F., Hiernaux, J., Maroy, C., Rupuooy, D. \& Saint-Georges (Eds.), Práticas e métodos de investigação em ciências sociais (pp. 117155). Porto: Edições afrontamento.

Pereira, A., \& Matos, M. (2011). Avaliação Psicológica das responsabilidades parentais nos casos de separação e divórcio. In Matos, M., Gonçalves, R. \& Machado, C.(Coords.), Manual de Psicologia Forense: Contextos, práticas e desafios (pp. 311-347). Braga: Psiquilíbrios Edições.

Pereira, A. L., \& Matos, M. (2010). Separación y Divorcio: Litigio e interferencias parentales: Lecturas de jueces en casos de guarda y custodia. In F. Fariña, R. Arce, M. Novo y D. Seijo (Coord.), Separación y Divorcio: Interferencias parentales (pp. 225-240). Madrid: ASEMIP.

Pinto, A. (2002). Percepções e vivências femininas do processo de separação e divórcio. Dissertação de mestrado não publicada. Universidade do Minho. Braga.

Pinto, H. A., \& Pereira, G. (2005). Separação e divórcio: Um olhar no feminino. Coimbra: Quarteto.

Ramião, T. (2005). Organização Tutelar de Menores anotada e comentada (4⿳亠丷a ed.). Lisboa: Quid Juris.

Relvas, A. P., \& Alarcão, M. (2002). Novas formas de família. Coimbra: Quarteto.

Ribeiro, M., Sampaio, D., \& Amaral, J. (1992). Que Divórcio? (2ํod). Lisboa: Edições 70.

Ribeiro, M. (2006). Amor de pai: divórcio, falso assédio e poder paternal. Lisboa: Publicações D. Quixote.

Ribeiro, M. (2007). As crianças e o divórcio, 0 diário de Ana. Editorial presença.

Santos, E. (2003). Do divórcio: suas causas, processo e efeitos (3ํoe.). Lisboa: Associação académica da faculdade de direito.

Simões, M., Martins, R., \& Formosinho, M. (2006). Regulação do exercício do poder paternal: Aspectos jurídicos e avaliação psicológica. In Fonseca, A. (Coords,), Psicologia Forense (pp.496-518). Coimbra: Almedina.

Sottomayor, M., C. (1995). Exercício do poder paternal relativamente à pessoa do filho após o divórcio ou a separação judicial de pessoas e bens. Estudos e Monografias: Universidade Católica Portuguesa, Porto.

Sottomayor, M., C. (2004). Regulação do exercício do poder paternal nos casos de divórcio. Coimbra: Almedina.

Sottomayor, M. (2008). Regulação do exercício do poder paternal nos casos de divórcio (4ºed.). Coimbra: Almedina. 
Machado e Matos

Torres, A. C. (1996). Divórcio em Portugal, ditos e entreditos: uma análise sociológica. Cidade: Editora.

Historial do artigo

Recebido $\quad 06 / 07 / 2015$

Aceite $\quad 15 / 02 / 2016$

Publicado 06/2016 
Discursos dos magistrados acerca da prática pericial 